\title{
Analyzing and Evaluating Smart Cities for IoT Based on Use Cases Using the Analytic Network Process
}

\author{
Chao Huang $\mathbb{D}^{1}$ and Shah Nazir (D) $^{2}$ \\ ${ }^{1}$ Tianjin University of Technology, Tianjin 300384, China \\ ${ }^{2}$ Department of Computer Science, University of Swabi, Swabi, Pakistan \\ Correspondence should be addressed to Chao Huang; chaohuang_tjut@sina.com and Shah Nazir; snshahnzr@gmail.com
}

Received 28 December 2020; Revised 11 January 2021; Accepted 18 January 2021; Published 23 February 2021

Academic Editor: Mian Ahmad Jan

Copyright ( 2021 Chao Huang and Shah Nazir. This is an open access article distributed under the Creative Commons Attribution License, which permits unrestricted use, distribution, and reproduction in any medium, provided the original work is properly cited.

\begin{abstract}
With the passage of time, the world population is growing. Proper utilization of resources and other devices is tremendously playing an important role to easily examine, manage, and control the resources of the Internet of Things (IoT) in the smart city. Research in the field of IoT has revolutionized the services mostly in smart cities. In the smart city, the applications of IoT are utilized without human involvement. Diverse IoT devices are connected with each other and communicate for different tasks. With the existence of a huge number of IoT devices in the forthcoming years, the chances of privacy breach and information leakage are increasing. Billions of devices connected on IoT producing huge volume of data bound to cloud for processing, management, and storage. Sending of whole data to the cloud might create risk of security and privacy. Various needs of the smart city should be considered for both urgent and effective solutions to support requirements of the growing population. On the other side of rising technology, the IoT evolution has massively produced diverse research directions for the smart city. Keeping in view the use cases of the smart city, the proposed study presents the analytic network process (ANP) for evaluating smart cities. The approach of ANP works well in the situation of complexity, and vagueness exists among the available alternatives. The experimental results of the planned approach show that the approach is effective for evaluating the smart cities for IoT based on the use cases.
\end{abstract}

\section{Introduction}

With the passage of time, the population of the world is rising. According to the United Nations report, the population of the world will increase by 2.5 billion in 2050 . About 55\% of the world populations exists in cities, and it is estimated that, in the coming 30 years, this percentage will reach $68 \%$ [1]. Such incredible rise in population will give birth to diverse challenges and issues on cities. These issues can include sustainability management and urban areas development of smart cities. Research in the field of IoT has revolutionized the services mostly in smart cities. In the smart city, the applications of IoT are utilized without human involvement. Diverse IoT devices are connected with each other and communicate for different tasks. With the existence of a huge number of IoT devices in the forthcoming years, the chances of privacy breach and information leakage are increasing. Billions of devices connected on IoT producing huge volume of data bound to cloud for processing, management, and storage. Sending of whole data to the cloud might create risk of security and privacy. The paradigm of cloud computing subjugated through fog computing and acted as a channel between cloud and IoT.

Various approaches are being practiced by practitioners and researchers for diverse issues of smart cities. Sadhukhan [2] proposed an approach as appropriate framework for the services of smart city relying on IoT for addressing the issues of internet connectivity in smart city and to deal with heterogeneous technologies. Sabrina [3] proposed a model of structural relationship-based access control that can be used as an agent for the access of rights to resources for users 
in the scenario of IoT at large scale. The model used public blockchain and smart contracts to manage access control for users that are external and with a local off-blockchain storage to manage access control for internal users of the organization. Lee et al. [4] suggested the function of service platform and whole architecture with details of the uses of platform with the help of analyzing road surface as a case study. The study analyzed the data services which can be associated with the applications of smart city and recommended generic directions of the services of urban data for services of advanced city. Li et al. [5] presented a semiautomated process of role mapping for the setting of dynamic accesses of smart city enabling access control. Mora-Sánchez et al. [6] proposed scalability complaint infrastructure as a validation approach consisting of the properties of interoperability, modularity, and resilience. The approach is relying on the top practices accomplished during a living lab at the Smart Cities Innovation Center in Universidad de Guadalajara implementation. Gebru et al. [7] addressed the prospect of quantifying flow and detection of people in the street of city to implementation of commercial sensors linked with the network of $5 \mathrm{G}$ capturing analyses of $\mathrm{WiFi}$ communicated through smartphones of people. The issues and motivation of these scenarios were outlined. After this, the study illustrated the proposed approach and presented the results obtained from live measurement in a testbed employed in Turin city within the project of 5G-EVE. The contributions of the planned study are given as follows:

(i) To present the ANP approach for assessing smart cities

(ii) To plot the smart cities according to the criteria defined for the available alternatives to achieve a specific goal of smart city

(iii) Results of the proposed approach show that the approach is effective for evaluating the smart cities for IoT based on the use cases

The paper is organized as follows: Section 2 shows the literature on the diverse issues of the smart cities. Section 3 briefly shows the methodology with the background of the smart cities use cases and the approach of the ANP for assessing the smart cities. The paper is concluded in Section 4.

\section{Related Work}

Various approaches are in practice by researchers and practitioners for smart city. Rout et al. [8] presented a model of IoT network based on technique of fuzzy logic data fusion for IoT. The process of data fusion estimates the congestion of location specific through human input and sensory data from the crowd. An open-source routing engine computes the congestion-aware shortest route through retorting to live updates of traffic in network of road. Besides, a node of sensor has been intended to gather the speed and emissions of moving vehicles on the road. An Android application was developed for gathering information of blockage on the road. Gheisari et al. [9] presented the concept of software defined networking paradigm to equip the IoT based smart city. The approach mounts privacy preserving for accomplishing packets of data flowing of split IoT device data. Several simulations were done by Mininet-WiFi for showing efficiency of the approach. Alamgir Hossain et al. [10] have used the concept of edge computing for empowering state awareness in IoT based smart city and for minimizing the latency of the edge devices producing data to be moved to cloud. From the user endpoint, huge data is produced, so processing of this data can expressively increase performance. The results of the experiments showed that processing IoT raw data at the devices of edge delivers situational awareness and is efficient for latency smart city decision makers. Araujo et al. [11] studied the performance assessment of FIWARE, which is a platform of cloud based IoT. The results were gathered from widespread performance assessment and developed testbed and produced MQTT and CoAp data for emulating IoT deployments at large scale.

Meng et al. [12] presented blockchain empowered single character frequency-based ESM building a confirmable database of malicious payloads through blockchain. In the assessment, the performance of the method was investigated under flooding character padding attacks in the real IoT and simulated surroundings. Sharma et al. [13] used multicriteria decision-making methods and acknowledged 15 implementations' IoT barriers from the existing literature hindering the implementation of IoT in smart cities in India. The acknowledged IoT barriers were investigated by approach of total interpretative structure model. The Fuzzy Matrices' Impacts Croises Multiplication Classement model, the decision-making trial, and evaluation laboratory approach were used. Serrano [14] presented blockchain random neural network for the applications of cybersecurity in a complete physical and digital cybersecurity user and channel methods of authentication. The approach empowers the gaps, the confidential identity can be mined, and attackers can be identified. Abbas et al. [15] achieved two objectives in the study: the first is the enhancement of Narrowband Internet of Things spectral efficiency, while the second one is to lessen the burden of signaling during transmission request for SMs. Koumetio Tekouabou et al. [16] proposed a system that integrated the predictive model based on ensemble approaches and IoT for optimizing the expectation of space availability in the smart parking. The Birmingham parking dataset was endorsed for reaching a Mean Absolute Error of $0.06 \%$ by applying Bagging regression. Pimpinella et al. [17] proposed smart urban routing services designed for cyclists and pedestrians disposed of movements in the city. The system allows retrieving the top route between a location of the source and destination based on the defined objective function of the user.

Srinivasa Desikan et al. [18] offered techniques of topology control for managing and constructing network of IoT for large-scale smart city. The problem of topology control was approached in two phases, the construction and maintenance. Based on fog gateways, cost-efficient IoT network was built in the construction phase, while resource utilization was done in the maintenance phase. Marques et al. 
[19] proposed a multilevel infrastructure management architecture for IoT based smart city. The issue of waste management was considered for evaluating the performance of the system. The experimental results of the study show that the idea of the architecture is capable of managing up to 3902 garbage bins instantaneously. Atitallah et al. [20] presented a comprehensive review of the existing literature associated with DL and IoT for developing smart cities. The study begins with defining the IoT and then lists the properties of IoT produced big data. Furthermore, the study presented various infrastructures of computing used for big data analytics of IoT consisting of fog, cloud, and edge computing. Additionally, they surveyed the common DL models and presented the current innovations employing both the DL and IoT for developing services and smart applications for smart cities. The issues and challenges that existed during the developments of smart cities are highlighted. Bibri [21] aimed to review the associated literature with the objective of finding and discussing the state-of-the-art applications of sensor based big data empowered through the IoT surrounding sustainability and platforms of associated data processing and models of computing for smart sustainable cities. The issues and challenges affecting analytics of big data and IoT were identified.

Zahmatkesh and Al-Turjman [22] considered the probable applications of fog computing and technologies toward sustainable smart cities in the environment of IoT. The study discussed different approaches of artificial intelligence, various techniques of caching, unmanned aerial vehicle, and machine learning in data caching for fog based IoT. The study also highlighted the issues and challenges faced by the system. Singh et al. [23] provided a detailed review of the literature of the problems and issues impacting the blockchain deployment in smart cities. The study presented review of the main factors to the blockchain convergence and technologies of IoT for supporting a sustainable smart society. The study also discussed the solutions of security improvements and summarized the different main points that can be used to develop different transportation system based on AI-enabled blockchain. Majumdar et al. [24] predicted the congestion propagation across network of road based on long-short memory. The model predicts the propagation of congestion according to speed of vehicle from sensors of traffic at two sites. Rani et al. [25] presented a review on the cloud ecosystem and IoT role in smart cities with evaluation parameters and forthcoming directions of research in smart cities. Ouerhani et al. [26] offered an approach of dynamic control and management for streetlight based on architecture of IoT. Considerable influence is carried out for the interoperability level through the idea of device connection relying on communication of model driven agents for speeding up the cooperation of actuators and sensors to platform of IoT. The experimental results from tests of the real world with employed dynamic streetlights in urban spaces are shown.

Merlino et al. [27] presented an approach for the design and implementation of software defined cities approach which is a cloud infrastructure initiated from the idea of software-defined paradigms. The architecture in focus is on aspect of infrastructure and function virtualization with details of software stacks used. Santos et al. [28] presented PortoLivingLab, an infrastructure of multisource sensing that influences technology of IoT for achieving four occurrences of city-scale sensing. These occurrences include environment, weather, people flows, and public transport. A vehicular network is deployed, containing 600 vehicles and 19 environmental static sensors. Platform of crowdsensing that is effortlessly reconfigurable is conceded to various crowdsensing campaigns with above 600 participants. The architecture and elements of PortoLivingLab mentioning the technologies of IoT and issues faced are described. Various use cases are presented as evidence of idea. Omarov and Altayeva et al. [29] offered an approach of multiagent based implementation of smart microgrid that can be a base in building smart city converged platform. Mora et al. [30] proposed a blockchain as a potential for conciliating privacy versus security. The approach discussed the initial employment of a control access system incorporating blockchain. The study discussed the advantages and issues in detail.

\section{Methodology}

The following sections describe the methodology section of the paper.

3.1. Identification of Use Cases for Smart Cities. The world population is growing with the passage of time. Resources utilization and other devices are tremendously playing a significant role to certainly analyze, manage, and control the resources of the IoT in the smart city. In smart city, the applications of IoT are utilized without human involvement. Diverse IoT devices are connected with each other and communicate for different tasks. Figure 1 shows the depiction of smart city ecosystem, which demonstrates how data are accumulated from smart sensors of edge then transforming to the cloud and fog for processing, management, and storage and then interpreting for serving various applications of IoT [20].

Diverse sectors through the city have in recent times expanded the capability of smart technologies and actions $[20,31,32]$. These sectors of smart cities are given as follows:

(i) Smart homes: these are the residence containing devices connected to the internet. These devices can include lights, fridges, and televisions, communicating with each other and sharing the data to its users.

(ii) Smart healthcare: the smart healthcare consists of the devices that can monitor and measure the activities of user health. These devices are mostly wearable and nonwearable, which can measure user temperature, user blood pressure, heartbeat rate, blood sugar, and many other diseases.

(iii) Smart environment: intelligent sensors are installed for the development of city infrastructure. These sensors control and monitor the conditions of the surroundings for providing healthier environment. 


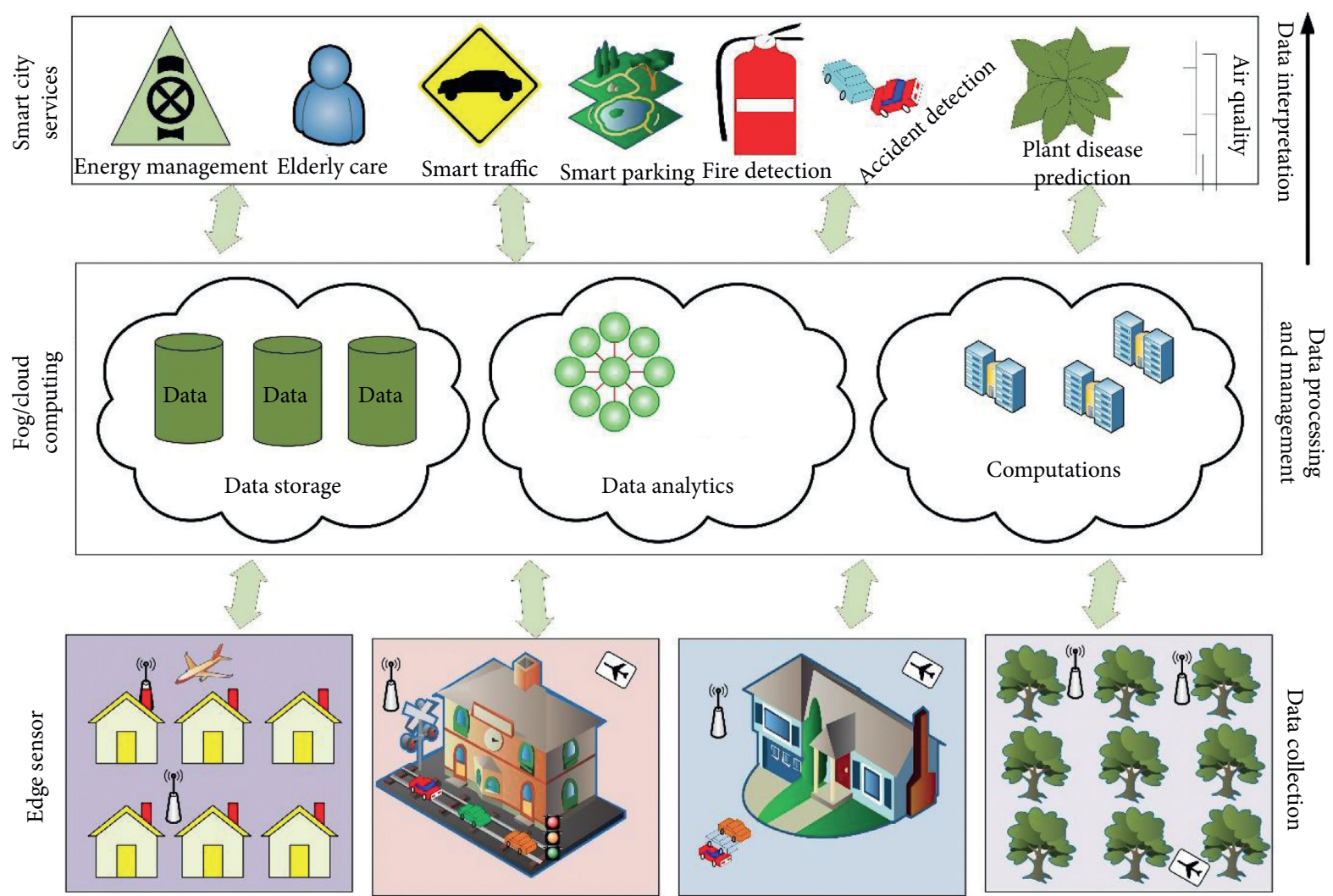

FIGURE 1: Smart city ecosystem.

(iv) Smart transportation: optimized services and innovative devices are used for enhancement of smart cities transportation. The services are smart parking, traffic flow, and so on.

(v) Smart surveillance: diverse devices of surveillance such as camera are installed for prevention of incidents. Smart security can be achieved by collecting real-time data and then analyzing it for different purposes.

(vi) Smart agriculture: the deployment of IoT devices in agriculture is for automation and providing good services against outdated approaches. These services support the agriculture and guarantee healthier crop production and improve harvesting, smart crop counting, and so on.

The proposed study has considered the six use cases from hypothetical smart cities which were earlier identified $[31,32]$. These use cases are smart home, smart transportation, smart healthcare, smart environment, smart agriculture, and smart surveillance. These use cases of smart cities are described in Figure 2.

3.2. Analyzing the Smart Cities Based on Use Cases. Various libraries were searched for identification of relevant materials associated with the proposed study. The search results indicate that the extent of research is increasing in the field of smart cities. Various types of analysis were done. These types of analysis include the years of publication with papers published, the type of articles, the place, and titles of publications. Figure 3 shows the papers with the years of publication in ScienceDirect.

Figure 4 shows the paper types in the same library.

Figure 5 presents the discipline of publications. In the figure, it is revealed that a high number of papers were published in the field of computer science.

Figure 6 shows locations of conference held with the articles number in the IEEE.

Figure 7 graphically shows the topics of publications.

Figure 8 depicts the types of papers.

Figure 9 depicts the publications with the disciplines in the Springer library.

Figure 10 shows the publication types in the same library.

3.3. Evaluating Smart Cities for IoT Based on Use Cases. Researches in the area of IoT have transformed the services commonly in smart cities. In smart city, the applications of IoT are exploited deprived of human participation. Various devices of IoT are linked with each other, communicating for different activities and tasks. With the existence of a huge number of IoT devices in the forthcoming years, the chances of privacy breach and information leakage are increasing. Billions of devices connected on IoT producing huge volume of data bound to cloud for processing, management, and storage. Sending of whole data to the cloud might create risk of security and privacy. The proposed study considers 


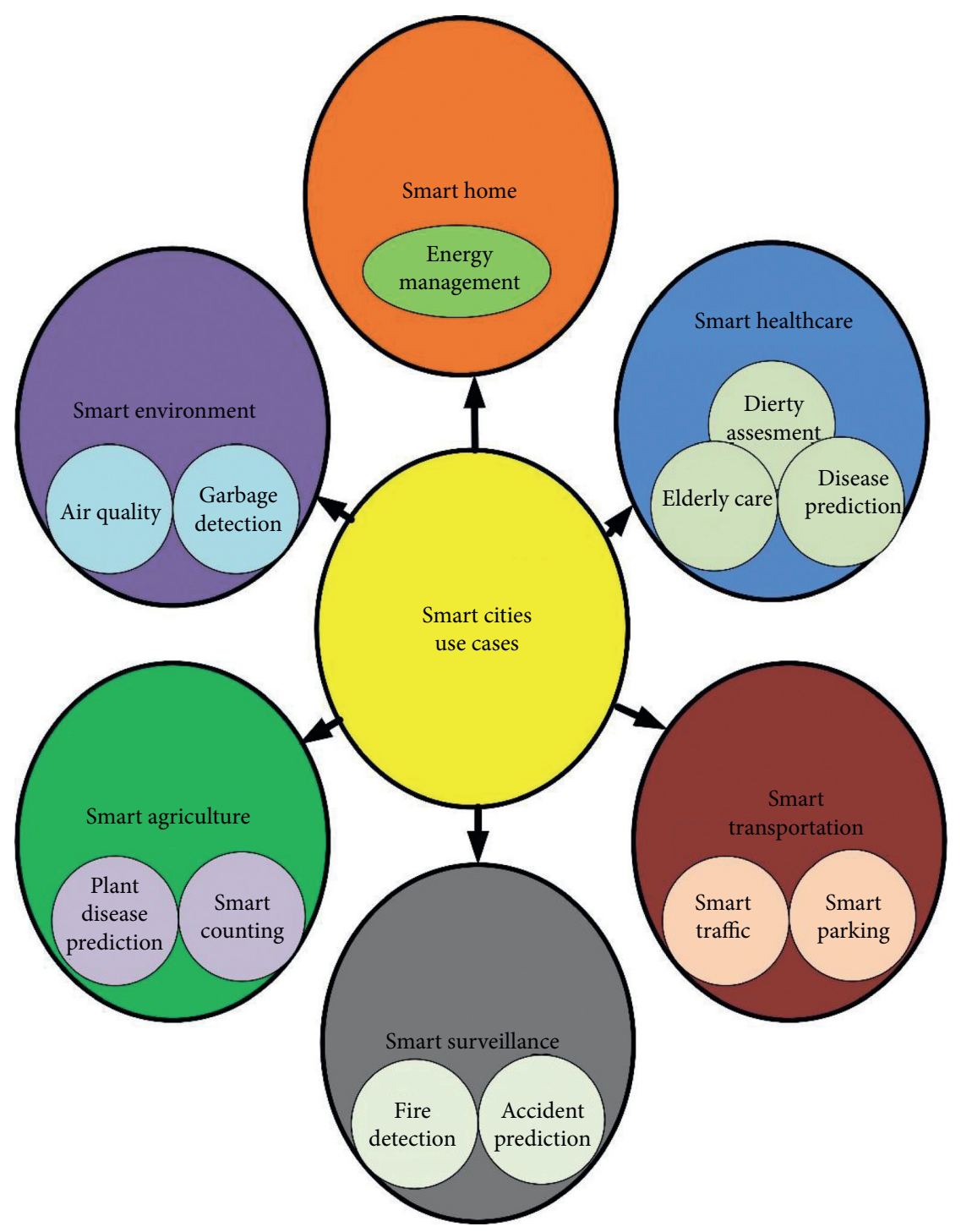

FIGURE 2: Smart cities' use cases.

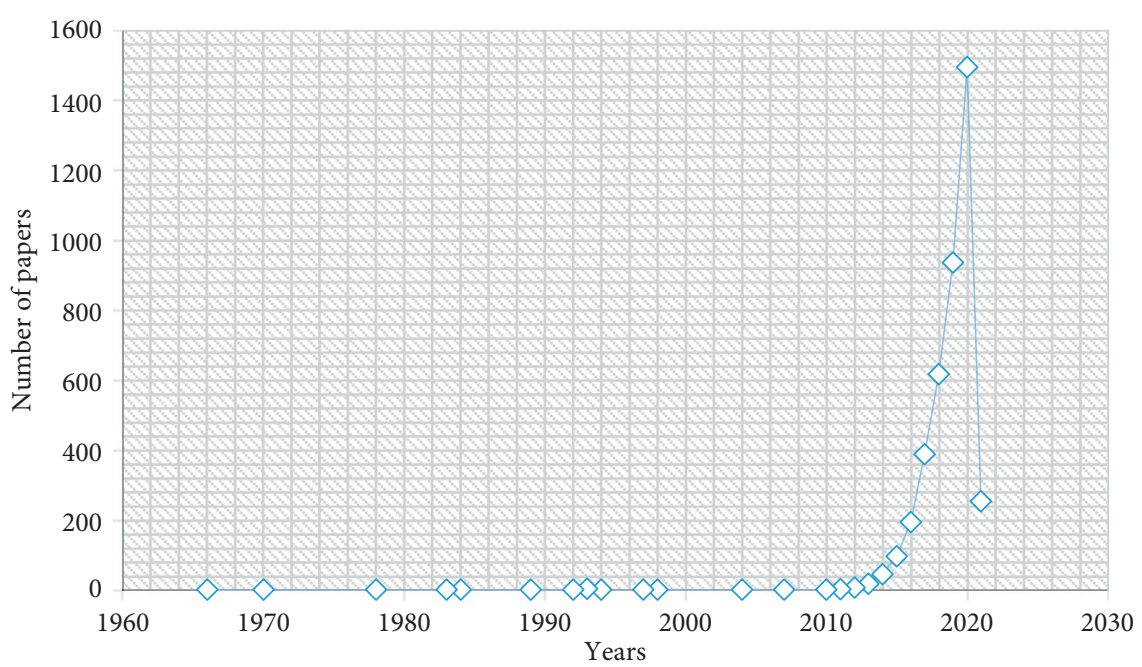

Figure 3: Years with publications. 


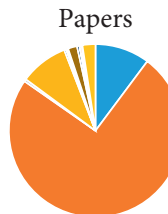
- Review articles
- Research articles
- Case reports
Book chapters
Conference abstracts
Discussion
- Conference info
- Data articles
- News
- Editorials
- Mini reviews
- Software publications
- Product reviews
- Short communications
- Others
- Encyclopedia

FIgUre 4: Publication types.

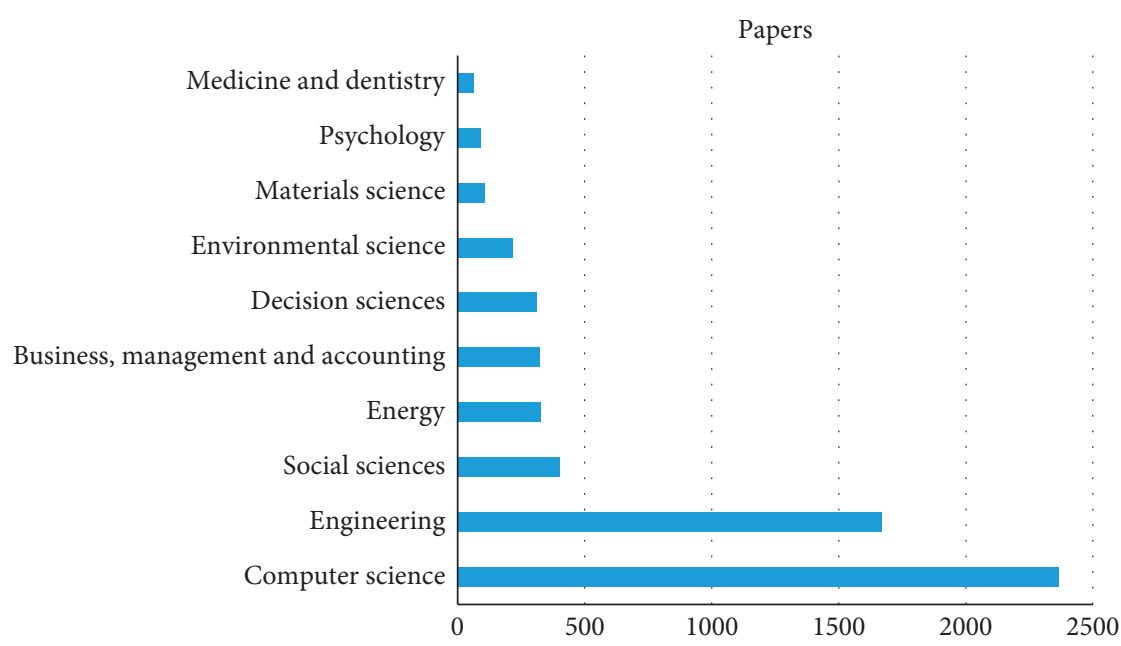

Figure 5: Disciplines of publications.

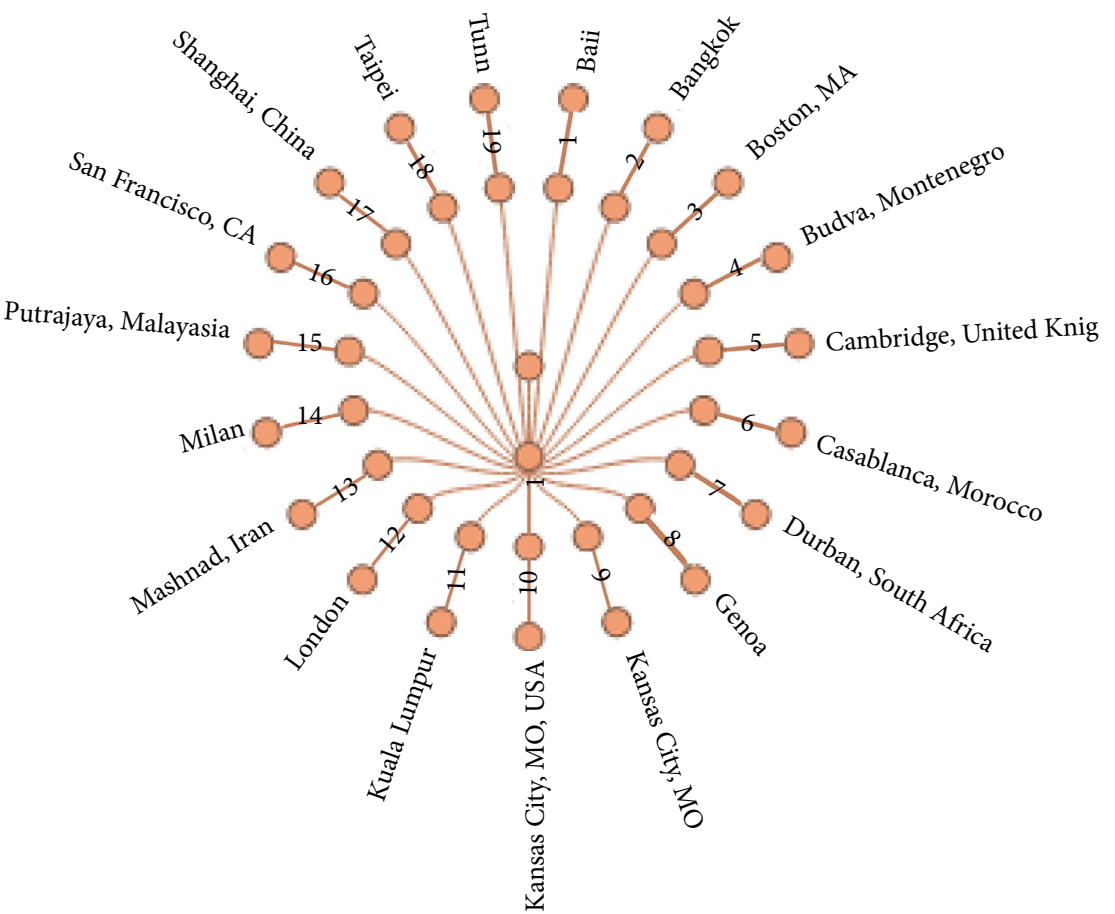

FIgURE 6: Locations of conferences held. 


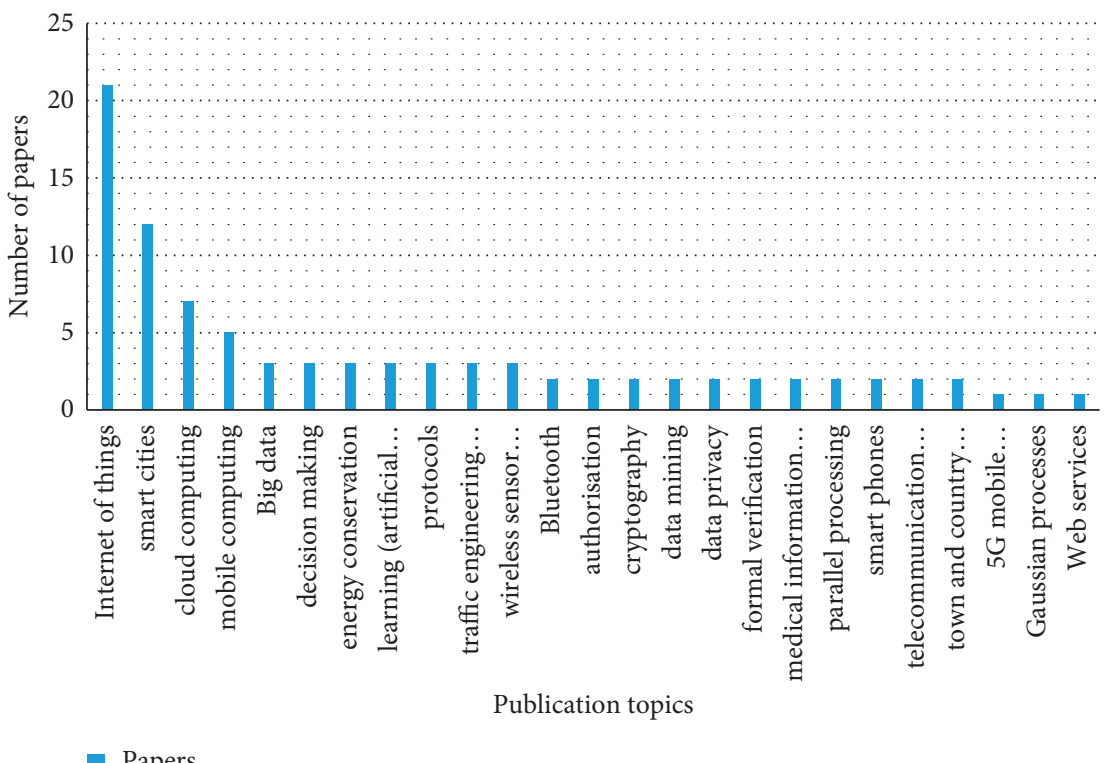

Figure 7: Publication topics.

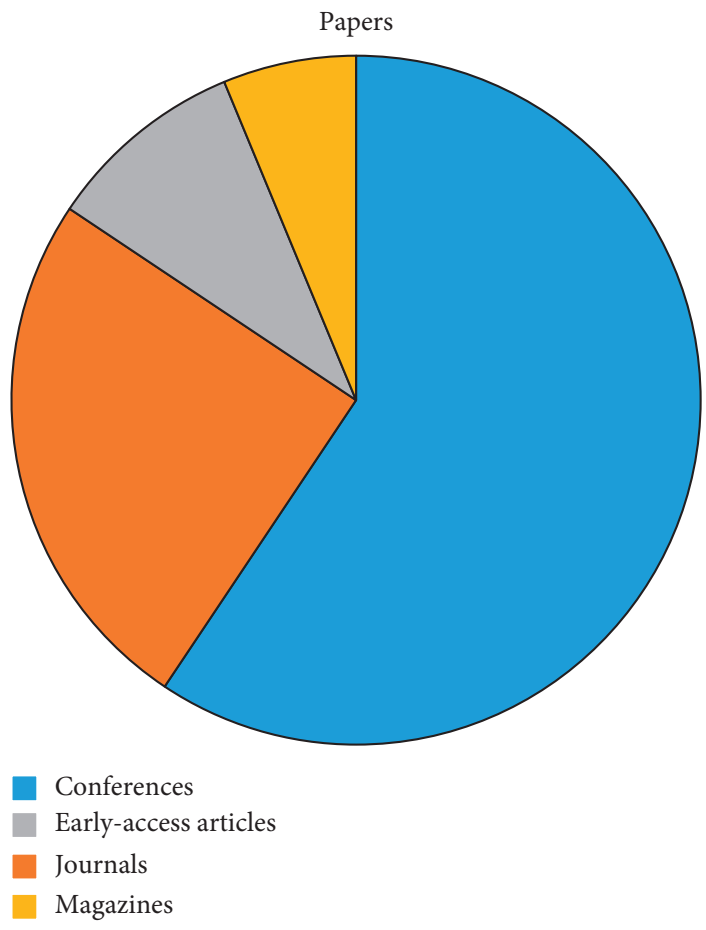

Figure 8: Publication types.

different use cases of the smart cities on the basis of which smart cities are assessed. These use cases are smart home, smart transportation, smart healthcare, smart environment, smart agriculture, and smart surveillance. The approach of ANP has been used for the purpose of evaluation of the smart cities. The ANP has various applications [33-38]. Three parts of the approach were considered as the significant parts consisting of goal, criteria, and alternatives. The details of the ANP approach can be found in [39]. The following algorithm was followed for the process of evaluation of the proposed study (Algorithm 1).

The process of the above algorithm was followed to evaluate the smart cities. The random consistency table was given by Satty [39] (Table 1).

The process of calculating the pairwise comparison was done for each of the alternatives and criteria to achieve the goal of smart city. The whole process of calculation was done but here only a few tables are given for understanding of the 


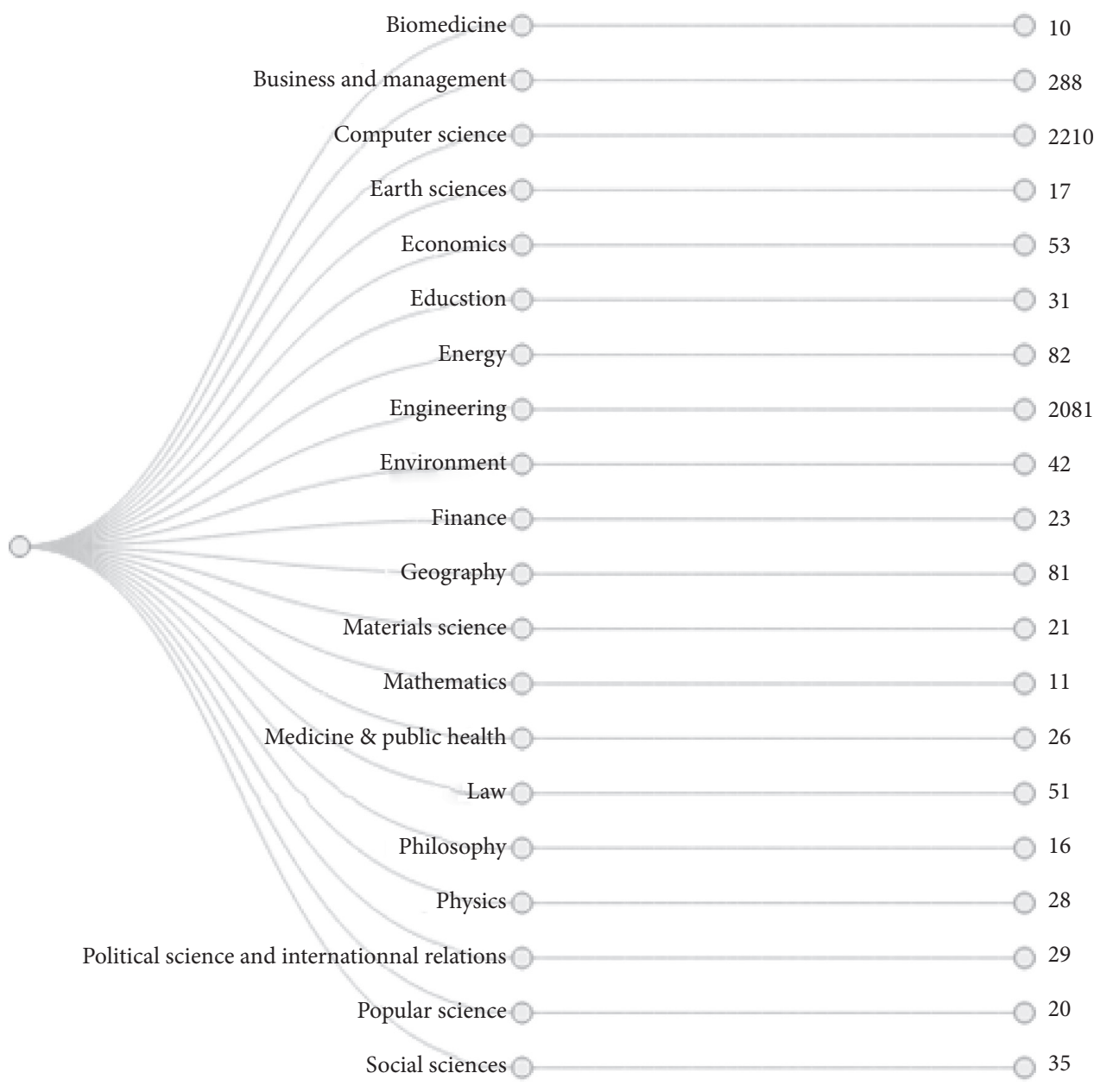

FIgURE 9: Papers with disciplines.

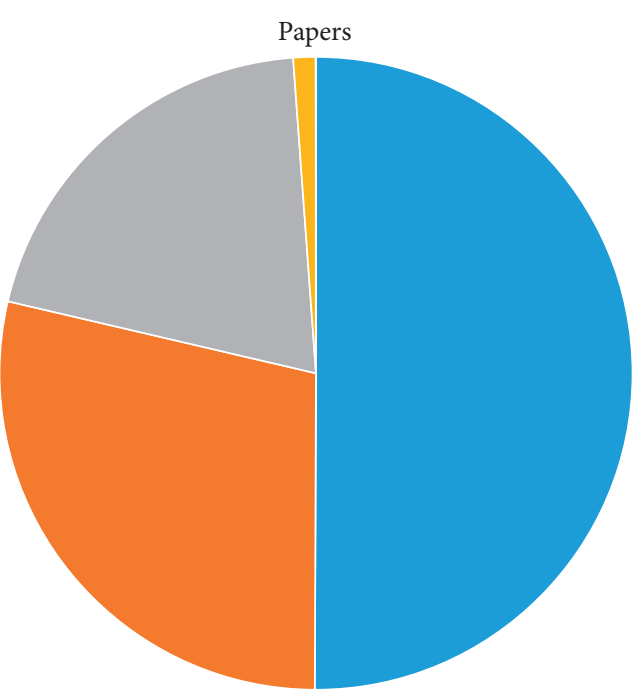

Chapter

Article

Protocol

Conference paper

Reference work entry

Figure 10: Publication types. readers. Table 2 shows the pairwise comparison of smart city 1 for available use cases.

The process in Table 2 is normalized, and the normalization process is shown in Table 3.

Table 4 shows the available smart cities which are evaluated for the use cases.

Table 4 is normalized, and the normalized table is shown in Table 5 .

After all of the processes of pairwise comparison, the normalized matrices are combined into a single matrix, which formed a weighted supermatrix. The weighted supermatrix is shown in Table 6.

The weighted supermatrix was converted into limit matrix for decision-making. This table was obtained by taking the square of the weighted matrix till all the values of rows become the same. Table 7 shows the limit matrix.

On the basis of the limit matrix given in Table 7 , the decision of smart cities can be made. This decision was graphically plotted for showing visibility of the decision of evaluation of smart cities based on use cases. The smart city SC1 obtained high rank of 0.453 followed by SC2 and then others. So, among the available smart cities, SC1 was considered the topmost priority. Figure 11 shows the ranking of the smart cities against the available based on the use cases. 

(a) Plot the criteria into subparts
(b) Qualitative scale of measure between 1 and 9
(c) Pairwise comparison is done
(d) Relative importance is found
(e) Finding the principal eigenvalue and the related eigenvector of the matrix
(f) Measuring the consistency of the matrix
(g) Priority vector " $w$ " is calculated as follows: $A_{w}=\lambda_{\max } w$
(h) $\lambda_{\max }$ is the major eigenvalue of matrix " $A$ " and " $w$ " is its eigenvector.
(i) Calculating the consistency index (CI) and consistency random (CR) of the pairwise comparison matrix computed by the following equation: $C_{i}=\left(\lambda_{\max }-n\right) /(n-1), \mathrm{CR}=\mathrm{CI} / \mathrm{RI}$
(j) The value of CR should be less than 0.1
(k) Construction of the supermatrix
(l) Conversion of the weighted supermatrix into the limit matrix
(m) Decision based on the limit matrix

Algorithm 1: Process of the proposed approach.

TABLE 1: Random consistency index.

\begin{tabular}{|c|c|c|c|c|c|c|c|c|c|c|c|c|c|c|c|}
\hline & 1 & 2 & 3 & 4 & 5 & 6 & 7 & 8 & 9 & 10 & 11 & 12 & 13 & 14 & 15 \\
\hline RI & 0 & 0 & 0.58 & 0.9 & 1.12 & 1.24 & 1.32 & 1.41 & 1.45 & 1.49 & 1.51 & 1.48 & 1.56 & 1.57 & 1.59 \\
\hline
\end{tabular}

TABle 2: Pairwise comparison of smart city 1 for available use cases.

\begin{tabular}{|c|c|c|c|c|c|c|}
\hline & Smart home & Smart healthcare & Smart transportation & Smart surveillance & Smart environment & Smart agriculture \\
\hline Smart home & 1 & 3 & 2 & 5 & 4 & 4 \\
\hline Smart healthcare & $1 / 3$ & 1 & 2 & 3 & 2 & 3 \\
\hline Smart transportation & $1 / 2$ & $1 / 2$ & 1 & 3 & 3 & 2 \\
\hline Smart surveillance & $1 / 5$ & $1 / 3$ & $1 / 3$ & 1 & 2 & 2 \\
\hline Smart environment & $1 / 4$ & $1 / 2$ & $1 / 3$ & $1 / 2$ & 1 & 3 \\
\hline Smart agriculture & $1 / 4$ & $1 / 3$ & $1 / 2$ & $1 / 2$ & $1 / 3$ & 1 \\
\hline
\end{tabular}

TABle 3: Normalization of Table 2.

\begin{tabular}{|c|c|c|c|c|c|c|c|}
\hline & $\begin{array}{l}\text { Smart } \\
\text { home }\end{array}$ & $\begin{array}{c}\text { Smart } \\
\text { healthcare }\end{array}$ & $\begin{array}{c}\text { Smart } \\
\text { transportation }\end{array}$ & $\begin{array}{c}\text { Smart } \\
\text { surveillance }\end{array}$ & $\begin{array}{c}\text { Smart } \\
\text { environment }\end{array}$ & $\begin{array}{c}\text { Smart } \\
\text { agriculture }\end{array}$ & E.V. \\
\hline Smart home & 0.39 & 0.53 & 0.32 & 0.38 & 0.32 & 0.267 & 0.371 \\
\hline Smart healthcare & 0.13 & 0.18 & 0.32 & 0.23 & 0.16 & 0.200 & 0.204 \\
\hline $\begin{array}{l}\text { Smart } \\
\text { transportation }\end{array}$ & 0.20 & 0.09 & 0.16 & 0.23 & 0.24 & 0.133 & 0.176 \\
\hline Smart surveillance & 0.08 & 0.06 & 0.05 & 0.08 & 0.16 & 0.133 & 0.094 \\
\hline Smart environment & 0.10 & 0.09 & 0.05 & 0.04 & 0.08 & 0.200 & 0.093 \\
\hline Smart agriculture & 0.10 & 0.06 & 0.08 & 0.04 & 0.03 & 0.067 & 0.062 \\
\hline
\end{tabular}
$\mathrm{CR}=0.78$.

TABLE 4: Available smart cities for use cases.

\begin{tabular}{lcccc}
\hline & SC1 & SC2 & SC3 & SC4 \\
\hline SC1 & 1 & 2 & 4 & 2 \\
SC2 & $1 / 2$ & 1 & 2 & 3 \\
SC3 & $1 / 4$ & $1 / 2$ & 1 & 2 \\
SC4 & $1 / 2$ & $1 / 3$ & $1 / 2$ & 1 \\
\hline
\end{tabular}

TABLE 5: Normalization of Table 4.

\begin{tabular}{llllll}
\hline & SC1 & SC2 & SC3 & SC4 & E.V. \\
\hline SC1 & 0.44 & 0.52 & 0.53 & 0.25 & 0.437 \\
SC2 & 0.22 & 0.26 & 0.27 & 0.38 & 0.281 \\
SC3 & 0.11 & 0.13 & 0.13 & 0.25 & 0.156 \\
SC4 & 0.22 & 0.09 & 0.07 & 0.13 & 0.125 \\
\hline
\end{tabular}




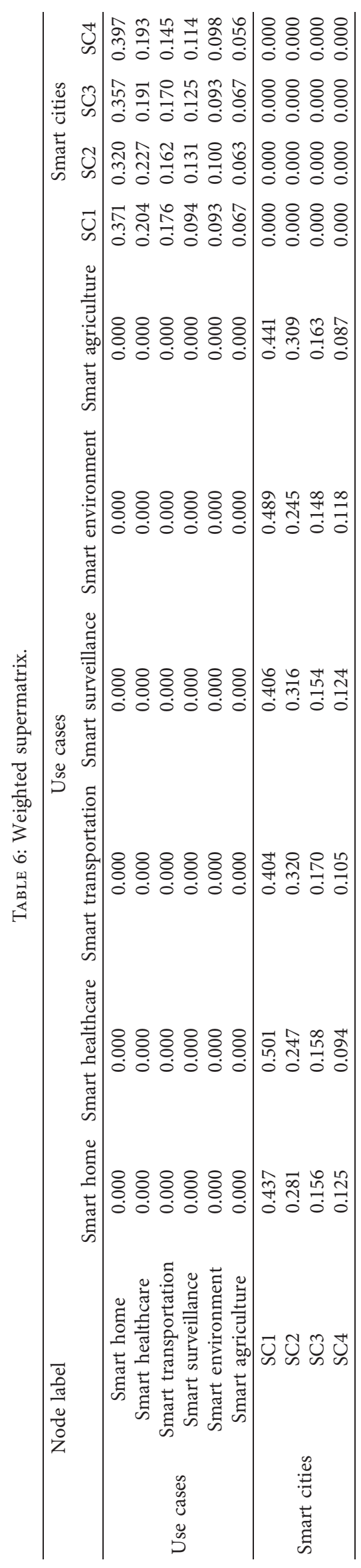


TABLe 7: Limit matrix.

\begin{tabular}{|c|c|c|c|c|c|c|c|c|c|c|c|}
\hline & \multicolumn{6}{|c|}{ Use cases } & \multicolumn{5}{|c|}{ Smart cities } \\
\hline & Node label & $\begin{array}{c}\text { Smart } \\
\text { healthcare }\end{array}$ & $\begin{array}{c}\text { Smart } \\
\text { healthcare }\end{array}$ & $\begin{array}{c}\text { Smart } \\
\text { transportation }\end{array}$ & $\begin{array}{c}\text { Smart } \\
\text { surveillance }\end{array}$ & $\begin{array}{c}\text { Smart } \\
\text { environment }\end{array}$ & $\begin{array}{c}\text { Smart } \\
\text { agriculture }\end{array}$ & SC1 & SC2 & SC3 & SC4 \\
\hline \multirow{6}{*}{$\begin{array}{l}\text { Use } \\
\text { cases }\end{array}$} & Smart home & 0.361 & 0.361 & 0.361 & 0.361 & 0.361 & 0.361 & 0.000 & 0.000 & 0.000 & 0.000 \\
\hline & $\begin{array}{c}\text { Smart } \\
\text { healthcare }\end{array}$ & 0.209 & 0.209 & 0.209 & 0.209 & 0.209 & 0.209 & 0.000 & 0.000 & 0.000 & 0.000 \\
\hline & $\begin{array}{c}\text { Smart } \\
\text { transportation }\end{array}$ & 0.169 & 0.169 & 0.169 & 0.169 & 0.169 & 0.169 & 0.000 & 0.000 & 0.000 & 0.000 \\
\hline & $\begin{array}{c}\text { Smart } \\
\text { surveillance }\end{array}$ & 0.113 & 0.113 & 0.113 & 0.113 & 0.113 & 0.113 & 0.000 & 0.000 & 0.000 & 0.000 \\
\hline & $\begin{array}{c}\text { Smart } \\
\text { environment }\end{array}$ & 0.096 & 0.097 & 0.096 & 0.097 & 0.097 & 0.097 & 0.000 & 0.000 & 0.000 & 0.000 \\
\hline & $\begin{array}{c}\text { Smart } \\
\text { agriculture }\end{array}$ & 0.065 & 0.065 & 0.065 & 0.065 & 0.065 & 0.065 & 0.000 & 0.000 & 0.000 & 0.000 \\
\hline \multirow{4}{*}{$\begin{array}{l}\text { Smart } \\
\text { cities }\end{array}$} & SC1 & 0.000 & 0.000 & 0.000 & 0.000 & 0.000 & 0.000 & 0.453 & 0.452 & 0.452 & 0.452 \\
\hline & SC2 & 0.000 & 0.000 & 0.000 & 0.000 & 0.000 & 0.000 & 0.287 & 0.287 & 0.287 & 0.287 \\
\hline & SC3 & 0.000 & 0.000 & 0.000 & 0.000 & 0.000 & 0.000 & 0.161 & 0.160 & 0.160 & 0.160 \\
\hline & SC4 & 0.000 & 0.000 & 0.000 & 0.000 & 0.000 & 0.000 & 0.114 & 0.114 & 0.114 & 0.114 \\
\hline
\end{tabular}

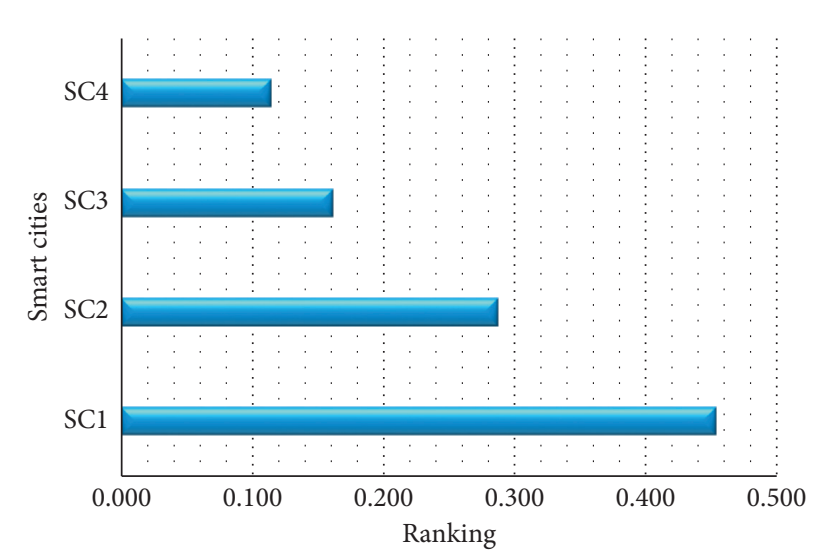

FIGURE 11: Ranking of smart cities based on the use cases.

\section{Conclusion}

Research in the field of IoT has transfigured the services of life, mostly in smart cities. In the smart city, the applications of IoT are utilized without human involvement. Various devices of IoT are connected with each other and communicate for different tasks. Billions of devices connected on IoT producing huge volume of data bound to cloud for processing, management, and storage. Sending of whole data to the cloud might create risk of security and privacy. Various needs of the smart city should be considered for both the urgent and effective solutions to support requirements of the growing population. On the other side of rising technology, the IoT developments have enormously shaped diverse research directions for the smart city. Keeping in view the use cases of the smart city, the proposed study presents the approach of the ANP for evaluating smart cities. The method was mainly based on the criteria defined for the smart cities with the aim of selecting the smart city. The selection of the smart city can further play an important role for living in the future. The experimental results of the proposed study show that the approach is effective for evaluating the smart cities for IoT based on the use cases.

\section{Data Availability}

The data can be provided upon request.

\section{Conflicts of Interest}

The authors declare no conflicts of interest.

\section{Acknowledgments}

This work was sponsored in part by Tianjin Philosophy and Social Science Project 2018 (TJYJ18-019).

\section{References}

[1] U. Nation, " $68 \%$ of the world population projected to live in urban areas by 2050," 2018, https://www.un.org/development/ desa/en/news/population/2018-revision-of-world-urbanizationprospects.html. 
[2] P. Sadhukhan, "An IoT based framework for smart city services," in Proceedings of the 2018 International Conference on Communication, Computing and Internet of Things (IC3IoT), vol. 15-17, pp. 376-379, Chennai, India, Febuary 2018.

[3] F. Sabrina, "Blockchain and structural relationship based access control for IoT: a smart city use case," in Proceedings of the 2019 IEEE 44th Conference on Local Computer Networks (LCN), pp. 137-140, Osnabrück, Germany, October 2019.

[4] R. Lee, R.-Y. Jang, M. Park, G.-Y. Jeon, J.-K. Kim, and S.-H. Lee, "Making IoT data ready for smart city applications," in Proceedings of the 2020 IEEE International Conference on Big Data and Smart Computing (BigComp), vol. 19-22, pp. 605-608, Busan, South Korea, Febuary 2018.

[5] F. Li, H. Wang, L. Diao, I. Yen, and F. Bastani, "Toward semiautomated role mapping for IoT systems in smart cities," in Proceedings of the 2019 IEEE International Smart Cities Conference (ISC2), pp. 14-17, Casablanca, Morocco, October 2019.

[6] O. B. Mora-Sánchez, E. López-Neri, E. J. Cedillo-Elias, E. Aceves-Martínez, and V. M. Larios, "Validation of IoT infrastructure for the construction of smart cities solutions on living lab platform," IEEE Transactions on Engineering Management, vol. 9910 pages, 2020.

[7] K. Gebru, C. Casetti, C. F. Chiasserini, and P. Giaccone, "IoTbased mobility tracking for smart city applications," in Proceedings of the 2020 European Conference on Networks and Communications (EuCNC), pp. 326-330, Dubrovnik, Croatia, Croatia, June 2020.

[8] R. R. Rout, S. Vemireddy, S. K. Raul, and D. V. L. N. Somayajulu, "Fuzzy logic-based emergency vehicle routing: an IoT system development for smart city applications," Computers \& Electrical Engineering, vol. 88, Article ID 106839, 2020.

[9] M. Gheisari, G. Wang, W. Z. Khan, and C. FernándezCampusano, "A context-aware privacy-preserving method for IoT-based smart city using software defined networking," Computers \& Security, vol. 87, Article ID 101470, 2019.

[10] S. Alamgir Hossain, M. Anisur Rahman, and M. A. Hossain, "Edge computing framework for enabling situation awareness in IoT based smart city," Journal of Parallel and Distributed Computing, vol. 122, pp. 226-237, 2018.

[11] V. Araujo, K. Mitra, S. Saguna, and C. Åhlund, "Performance evaluation of FIWARE: a cloud-based IoT platform for smart cities," Journal of Parallel and Distributed Computing, vol. 132, pp. 250-261, 2019.

[12] W. Meng, W. Li, S. Tug, and J. Tan, "Towards blockchainenabled single character frequency-based exclusive signature matching in IoT-assisted smart cities," Journal of Parallel and Distributed Computing, vol. 144, pp. 268-277, 2020.

[13] M. Sharma, S. Joshi, D. Kannan, K. Govindan, R. Singh, and H. C. Purohit, "Internet of Things (IoT) adoption barriers of smart cities' waste management: an Indian context," Journal of Cleaner Production, vol. 270, Article ID 122047, 2020.

[14] W. Serrano, "The blockchain random neural network for cybersecure IoT and 5G infrastructure in smart cities," Journal of Network and Computer Applications, vol. 175, Article ID 102909, 2021.

[15] A. M. Abbas, K. Y. Youssef, I. I. Mahmoud, and A. Zekry, "NB-IoT optimization for smart meters networks of smart cities: case study," Alexandria Engineering Journal, vol. 59, no. 6, 2020.

[16] S. C. Koumetio Tekouabou, E. A. Abdellaoui Alaoui, W. Cherif, and H. Silkan, "Improving parking availability prediction in smart cities with IoT and ensemble-based model," Journal of King Saud University-Computer and Information Sciences, 2020.

[17] A. Pimpinella, A. E. C. Redondi, and M. Cesana, "Walk this way! an IoT-based urban routing system for smart cities," Computer Networks, vol. 162, Article ID 106857, 2019.

[18] K. E. Srinivasa Desikan, V. J. Kotagi, and C. Siva Ram Murthy, "Topology control in fog computing enabled IoT networks for smart cities," Computer Networks, vol. 176, Article ID 107270, 2020.

[19] P. Marques, D. Manfroi, E. Deitos et al., “An IoT-based smart cities infrastructure architecture applied to a waste management scenario," Ad Hoc Networks, vol. 87, pp. 200-208, 2019.

[20] S. B. Atitallah, M. Driss, W. Boulila, and H. B. Ghézala, "Leveraging deep learning and IoT big data analytics to support the smart cities development: review and future directions," Computer Science Review, vol. 38, Article ID 100303, 2020.

[21] S. E. Bibri, "The IoT for smart sustainable cities of the future: an analytical framework for sensor-based big data applications for environmental sustainability," Sustainable Cities and Society, vol. 38, pp. 230-253, 2018.

[22] H. Zahmatkesh and F. Al-Turjman, "Fog computing for sustainable smart cities in the IoT era: caching techniques and enabling technologies - an overview," Sustainable Cities and Society, vol. 59, Article ID 102139, 2020.

[23] S. Singh, P. K. Sharma, B. Yoon, M. Shojafar, G. H. Cho, and I.-H. Ra, "Convergence of blockchain and artificial intelligence in IoT network for the sustainable smart city," Sustainable Cities and Society, vol. 63, Article ID 102364, 2020.

[24] S. Majumdar, M. M. Subhani, B. Roullier, A. Anjum, and R. Zhu, "Congestion prediction for smart sustainable cities using IoT and machine learning approaches," Sustainable Cities and Society, vol. 64, Article ID 102500, 2021.

[25] R. Rani, V. Kashyap, and M. Khurana, "Role of IoT-cloud ecosystem in smart cities : review and challenges," Materials Today: Proceedings, 2020.

[26] N. Ouerhani, N. Pazos, M. Aeberli, and M. Muller, "IoT-based dynamic street light control for smart cities use cases," in Proceedings of the 2016 International Symposium on Networks, Computers and Communications (ISNCC), pp. 1-5, Yasmine Hammamet, Tunisia, May 2016.

[27] G. Merlino, D. Bruneo, F. Longo, A. Puliafito, and S. Distefano, "Software defined cities: a novel paradigm for smart cities through IoT clouds," in Proceedings of the 2015 IEEE 12th Intl Conf on Ubiquitous Intelligence and Computing and 2015 IEEE 12th Intl Conf on Autonomic and Trusted Computing and 2015 IEEE 15th Intl Conf on Scalable Computing and Communications and Its Associated Workshops (UIC-ATC-ScalCom), vol. 10-14, pp. 909-916, Beijing, China, Auguest 2015.

[28] P. M. Santos, C. Queiros, S. Sargento et al., "PortoLivingLab: an IoT-based sensing platform for smart cities," IEEE Internet of Things Journal, vol. 5, no. 2, pp. 523-532, 2018.

[29] B. Omarov and A. Altayeva, "Towards intelligent IoT smart city platform based on OneM2M guideline: smart grid case study," in Proceedings of the 2018 IEEE International Conference on Big Data and Smart Computing (BigComp), pp. 701-704, Kyoto, Japan, January 2018.

[30] O. B. Mora, R. Rivera, V. M. Larios, J. R. Beltrán-Ramírez, R. Maciel, and A. Ochoa, "A use case in cybersecurity based in blockchain to deal with the security and privacy of citizens and smart cities cyberinfrastructures," in Proceedings of the 
2018 IEEE International Smart Cities Conference (ISC2), pp. 1-4, Kansas City, MO, USA, September 2018.

[31] M. M. Rathore, A. Paul, A. Ahmad, and S. Rho, "Urban planning and building smart cities based on the internet of things using big data analytics," Computer Networks, vol. 101, no. 63-80, 2016.

[32] R. Khatoun and S. Zeadally, "Smart cities," Communications of the ACM, vol. 59, no. 8, pp. 46-57, 2016.

[33] S. Nazir, S. Shahzad, I. Zada, and H. Khan, "Evaluation of software birthmarks using fuzzy analytic hierarchy process," in Proceedings of the Fourth International Multi-Topic Conference, pp. 171-175, 2015.

[34] S. Nazir, S. Shahzad, M. Nazir, and H. U. Rehman, "Evaluating security of software components using analytic network process," in Proceedings of the 11th International Conference on Frontiers of Information Technology (FIT), pp. 183-188, IEEE, Islamabad, Pakistan, December 2013.

[35] S. Nazir, S. Shahzad, Z. Hussain, M. Iqbal, and A. Keerio, "Evaluating student grades using analytic network process," Sindh University Research Journal (Science Series), vol. 47, no. 1, pp. 1-5, 2015.

[36] S. Nazir, S. Anwar, S. A. Khan et al., "Software component selection based on quality criteria using the analytic network process," Abstract and Applied Analysis, vol. 2014, Article ID 535970, 12 pages, 2014.

[37] J. Li, "Attributes based decision making for selection of requirements elicitation techniques using the analytic network process," Mathematical Problems in Engineering, vol. 2020, Article ID 2156023, 13 pages, 2020.

[38] X. Huang and S. Nazir, "Evaluating security of internet of medical things using the analytic network process methods," Security and Communication Networks, vol. 2020, Article ID 8829595, 14 pages, 2020.

[39] T. L. Saaty, "Relative measurement and its generalization in decision making why pairwise comparisons are central in mathematics for the measurement of intangible factors the analytic hierarchy/network process," Revista de la Real Academia de Ciencias Exactas, Fisicas y Naturales. Serie A. Matematicas, vol. 102, no. 2, pp. 251-318, 2008. 